\title{
OS OBJETOS TÉCNICOS E SEUS PAPÉIS NO HORIZONTE DAS HUMANIDADES DIGITAIS: UM CASO PARA A CIÊNCIA DA INFORMAÇÃO'
}

\author{
The Technical Objects and their roles in the Digital \\ Humanities horizon: a case for Information Science
}

\author{
Ricardo Medeiros Pimenta \\ ricardopimenta@ibict.br \\ Doutor em Memória Social e Documento pela \\ Universidade Federal do Estado do Rio de Janeiro. \\ Pesquisador Associado do Instituto Brasileiro de \\ Informação em Ciência e Tecnologia. Bolsista de \\ Produtividade em pesquisa 2.
}

RESUMO: As Humanidades Digitais são um campo auto-reflexivo capaz e desejante de que a aplicação das tecnologias digitais voltadas às Humanidades seja ela própria o objeto de investigação do pesquisador. Nesse sentido este artigo busca aproximar à ciência da informação a ideia de que nós devemos, uma vez que as Humanidades Digitais são marcadas pelas questões em torno das suas práxis e da techné que caracterizam-na, compor um canal de diálogo entre esses dois campos o quanto antes. De ordem teórica conceitual, este artigo se propõe a contribuir, portanto, com a inserção do tema e de sua problemática no processo reflexivo do campo da C.I., fundamentando como objeto/ator deste ponto de convergência o papel dos objetos técnicos, na perspectiva simondoniana, na sociedade da informação marcadamente contemporânea à era digital.

PALAVRAS-CHAVE: Humanidades digitais. Ciência da Informação. Simondon. Teoria. Digital.

ABSTRACT: Digital Humanities are a self-reflexive field capable of and desirous that the application of the digital technologies directed to the Humanities could be itself the object of researchers works. In this sense, this article seeks to bring to Information Science the idea that we should, once Digital Humanities are characterized by questions about their praxis and techné, compose a channel of dialogue between these two fields as soon as possible. From a theoretical and conceptual

1 Pesquisa realizada com recursos da Bolsa de Produtividade do CNPq. 
point of view, this article proposes to contribute, therefore, to the insertion of the theme and its problematic in the reflexive process of the Information Science field, having as a base as object/actor of this point of convergence the role of technical objects in an simondonian perspective, in the information society markedly contemporary to the digital age.

KEYWORDS: Digital Humanities. Information Science. Simondon. Theory. Digital.

\section{Introdução}

Vivemos em um era cujo apelo ao uso, consumo e reprodução de informações digitais já constituíram parte ordinária do dia-a-dia de muitos. Tal constatação não é nova, uma vez que Negroponte (1995) já havia escrito em seu livro “A vida digital”, de maneira quase visionária, as mudanças com que lidaríamos todos a partir da crescente interação da vida humana com os bits. De fato, não apenas na esfera profissional e pública, mas principalmente na privada, o recurso do uso de ferramentas digitais e de plataformas, softwares e suas interfaces diversas tomaram a doxa do homem mediano interferindo profundamente na cultura, na política e nas formas como produzimos conhecimento.

No campo científico não seria diferente. A ciência grosso modo se tornou cada vez mais alicerçada nos recursos tecnológicos que garantem não apenas sua divulgação, circularidade e dinâmica produtiva como também sua inovação. Do ponto de vista simondoniano, o que testemunhamos é nada mais do que o processo de “concretização" (SIMONDON, 1989), movimento "da técnica para a perfectibilidade, impossível de ser alcançada pela natureza" (SANTOS, 2008, p. 292) e que se mostra possível, em sua experiência sempre inacabada, processual, pela condição de metaestabilidade na qual nos encontramos todos, inclusive daqueles mesmos “objetos técnicos" (SIMONDON, 1989), agentes da concretização, que compõem e representam nossa tecnologia hodierna. Sendo assim, estes objetos, uma vez voltados às necessidades que o campo da ciência e seus diferentes espaços de interlocução produzem acabam por contribuir em muito para as possibilidades de divulgação e de maior/melhor visualização de seus resultados buscando a contínua produção do conhecimento.

Este, por sua vez, advém da apropriação e uso de informações que, no cenário atual rendem-se à estética digital como forma e meio pelo qual ela será acessada, 
compreendida, indagada. Um fenômeno sem precedentes quando refletimos sobre o incrível potencial da convergência nestes meios. Dados diferentes, advindos de bases e heterogêneas encontram por mediações tecnológicas possibilidades de produzir informações intercruzadas. Este fenômeno aparentemente banal é claramente visível quando observamos campos do conhecimento, e suas respectivas pesquisas, cuja configuração tradicional de suas práxis pareciam ainda distantes de recursos tecnológicos de ponta.

As ciências humanas são hoje o grande campo no qual a inserção da computação e de recursos diversos marcados pelo Big Data mais destacam tal inflexão multidisciplinar e que, talvez, para a Ciência da Informação mais aponte para a necessidade de ser por ela discutida uma vez que informação, seu acesso, suportes, sistemas, usuários, tanto em aspecto público como privado tornam-se elementos chave para compreender o que convencionou-se chamar de Humanidades Digitais (HD). "As humanidades digitais designam uma transdisciplina, portadora dos métodos, dos dispositivos e das perspectivas heurísticas ligadas ao digital no domínio das Ciências Humanas e Sociais" (THATCAMP, 2011).

Conhecida igualmente como Computing Humanities, as HD configuram-se, portanto como uma espécie de campo híbrido não apenas de estudo e pesquisa, mas de ensino e, principalmente de acesso à informação e inovação.

É neste mesmo campo híbrido que se destacam os conteúdos informacionais produzidos e circulantes nos espaço web informacionais (PIMENTA, 2016). Estes conteúdos podem representar e atuar direta e indiretamente na produção do conhecimento de qualquer área da ciência. De certo, para fins de objetividade deste artigo, buscamos dar destaque aqui ao caso das humanidades.

\section{Novas territorialidades: humanidades digitais e a ciência da informação}

Seria possível pensarmos e discutirmos as Humanidades Digitais sem o recurso do ciberespaço como lugar de convergência, acesso e circulação de suas atividades? Com efeito, o ciberespaço está repleto de espaços sociais que por sua vez reproduzem no universo digital e a partir dele categorias de saber das institucionais, tradicionais e científicas às populares e subterrâneas onde memórias e histórias se mesclam em 
uma diferente intelligentsia composta não unicamente por acadêmicos, mas através de uma nova e plural rede de estamento (no sentido weberiano) menos "duro", global e em formação contínua.

Com efeito, a utilização da internet e toda a informação que se produz nela e através dela convidou-nos a congregar de um novo espaço de ações do homem em sociedade. Este novo lócus não apenas o representa como se tornou sua grande ferramenta nas últimas décadas. Possivelmente até mais do que isso, se considerarmos o aspecto protético dos meios digitais e de suas tecnologias na vida prática e ordinária do homem contemporâneo. Em McLuhan (2011) encontramos tal apontamento como algo que apesar de "fatídico", é inerente à experiência humana. Seriam tais próteses também um recurso quase que compulsório às novas formas de se produzir conhecimento pelo campo da ciência? Tal constatação nos aproxima igualmente de Simondon (2005), pois é nele que buscamos o "conforto" de tal duro destino apontado em McLuhan (2011). Simondon (2005) aponta que, no tocante ao homem, o verdadeiro princípio da individuação é a mediação entre campos, energias e corpos. Para ele o homem é em si espaço teatral da individuação. Ou seja, o ser, enquanto um espaço, é um " de comunicação informativa. Ele é sistema em um sistema, comportando nele mesmo a mediação entre duas ordens de grandeza: a interna e a externa; subjetiva (ou psíquica) e coletiva; privada e pública. Donde se conclui que: (1) a gênese do ser, em perspectiva antropológica, não deveria ser pensada dissociada da tecnologia, pois ela, a tecnologia, é parte deste mesmo ser do ponto de vista simondoniano; (2) à medida que as produções tecnológicas engendram transformações no tecido socioeconômico, cultural e político da humanidade, determinam igualmente transformações no campo sensível, subjetivo e identitário do homem que se encontra, portanto sempre em processo de "individuação".

Dessa forma, é premente a reflexão sobre o papel das humanidades digitais enquanto expressão desse processo metaestável de construção do conhecimento mediado pela inovação e pela ascensão tecnológica às práxis diversas da investigação em humanidades. Não há volta no tocante ao crescente emprego de recursos tecnológicos diversos tanto nos métodos da pesquisa como para as formas de divulgação e acessibilidade que o pesquisador dará aos seus resultados via mediação digital. As Tecnologias de Informação e Comunicação (TIC) são extremamente presentes nesse processo e dessa forma está claro como tais fenômenos são potenciais objetos de 
pesquisa à ciência da informação. Afinal, é inegável certa mudança de paradigmas no tocante às práticas e meios comunicacionais disseminadores de informação ocorridos em consonância ao surgimento da internet e dos recursos digitais e que imporão novos limites devido à extensão e volume de informação (VAZ, 2004).

Como recordaremos de algo? Como recuperaremos uma informação necessária em meio a tanto excesso (PIMENTA, 2013, p. 7)? E como, efetivamente, nos relacionaremos com ela? E que informação será essa, no tocante as suas características? Isso certamente afetará o conhecimento de maneira geral e, mais precisamente, no campo das humanidades tal efeito talvez evidencie um maior impacto já que os sistemas, plataformas e objetos mediadores da informação digital não apenas reconfiguram conceitos e métodos no campo das humanidades, como nos convidam a exercitar um pensamento reflexivo sobre o papel dessas tecnologias de informação e comunicação (TIC) no próprio contexto da produção do conhecimento em campos então historicamente não familiarizados com tais mediações. A informação em seu formato digital juntamente com os objetos técnicos mediadores dessa mesma compõem, portanto, o conjunto "novo" e estruturante de elementos que interferirão no conhecimento sobre o homem em sociedade e seus fenômenos socioculturais.

De fato, e esse é um ponto de clara importância à compreensão do fenômeno do crescente desenvolvimento e interesse pelo campo das Humanidades Digitais, ao considerarmos o regime de informação vigente ao campo das ciências lato sensu, circunscrevendo aí questões de fomento, divulgação e circulação de atores e atividades; precisaremos ter igualmente em mente que sua comunicação, seus sistemas, tecnologias e linguagem se tornam igualmente objeto de pesquisa onde o Estado e o mercado se mostram como atores importantes para o seu desenvolvimento (GONZÁLEZ DE GÓMEZ, 2002).

Em 2010, durante evento em Paris voltado ao uso de tecnologias no campo das humanidades, The Humanities and Technology Camp (THATCamp), foi iniciado a ideia de uma construção coletiva de um documento, um manifesto, que pudesse expor à comunidade científica os avanços, objetivos e definições, ou mesmo identidade, do que viria a ser conhecido e mais disseminado como Humanidades Digitais. Este manifesto, intitulado "Manifesto das Humanidades Digitais” foi publicado em 2011 e atualizado em 2012 e se tornou um documento de referencia para a compreensão e reflexão sobre o papel, os objetivos e ética por trás desse novo 
campo que se compreende enquanto uma "transdisciplina, portadora dos métodos, dos dispositivos e das perspectivas heurísticas ligadas ao digital no domínio das Ciências humanas e sociais" (THATCAMP, 2011).

Cabe lembrar que as atividades de Humanidades Digitais (DH) são bem mais antigas e já estavam em profunda reflexão nos campos das ciência sociais, humanas, letras e artes. Duas importantes referências para melhor compreensão seriam o livro de Susan Schreibman, Ray Siemens e John Unsworth, "A Companion to Digital Humanities" (2004) e "Debates in the Digital Humanities" por Matthew K. Gold (2012).

De maneira sintética, a emergência das DH no cenário científico mundial é reflexo da escolha "da sociedade pelo digital altera e questiona as condições de produção e divulgação do conhecimento" (THATCAMP, 2011). Tal opção aponta ao fim e ao cabo, a constatação de que estamos já reestruturando as formas pelas quais acessamos e construímos os meios possíveis de produção de informação e conhecimento estritamente balizados nos recursos tecnológicos de ordem digital e que, em nossa perspectiva simondoniana, tais procedimentos afetarão amplamente nossas faculdades cognitivas ao mesmo ponto que nos desenvolvemos cada vez mais conectados.

Do ponto de vista da Ciência da Informação, é notório o avanço dos meios de produção e de disponibilização de informações em bibliotecas e em bases de dados diversas que contribuem para o patrimônio cultural (JORENTE; SILVA; PIMENTA, 2015), por exemplo, para o ensino, para a saúde pública ou para demais setores estratégicos da sociedade da informação e do conhecimento contemporânea onde mediação e desintermediação (ALMEIDA, 2014) marcam a cultura informacional global e contemporânea.

Um exemplo de atividades em HD no cenário brasileiro é o do processo de digitalização complexo, onde até mesmo se desenvolveu um software de reconhecimento de caracteres visando a melhor identificação e reprodução de textos antigos, assim como a criação de ferramentas descritoras e de metadados; ambos provenientes do acervo da Biblioteca Brasiliana Guita e José Mindlin, em São Paulo. Em todos os projetos é possível compreender que os questionamentos que "animam" tais atividades não são diferentes daqueles postos mais acima. Como recordar? Como recuperar? E de que forma? Com qual objetivo? Comunicar e informar de maneira 
polissêmica, via computação, aplicativos mobile, visualizações de massas de dados, indexação, reconhecimento imagético, de gráficos e grafias além de geo-referenciamento. Estes são alguns dos desdobramentos capazes de ser usados em um projeto de Humanidades Digitais. Todos impressões e expressões características de uma cultura informacional tecnológica marcada pelo fenômeno do digital em diferentes espaços e formas.

\section{Cultura e tecnologia para as humanidades digitais: um espaço relacional de concretização pela indagação e produção de conhecimento}

Quando pensamos em cultura, e em sua possível definição, vale considerar destarte que ela é uma forma, uma linguagem e igualmente resultado de uma gramática pela qual nos relacionamos com o real. É por ela que o homem regula sua relação com o mundo e consigo mesmo (SIMONDON, 1989, p. 227). E que comumente identificamos representada pelos artefatos e demais materialidades produzidas no tecido sócio-histórico (MARTELETO, 1995). Com efeito, a cultura deve ser pensada, portanto, enquanto fenômeno relacional não apenas entre humanos, mas entre eles e suas criações: as máquinas, objetos técnicos, tanto quanto seus conjuntos e sistemas, produtos da tecnologia.

Refletir sobre a tecnologia e tudo aquilo que se apresenta como expressão material/maquínica dela nos convida à reflexão de Gilbert Simondon, proposta em sua obra “Du mode d'existence des objets techniques" (1989). Em Simondon (1989) a compreensão da tecnologia requer a compreensão do ser desde sua ontogênese ao estado atual, inacabado; acompanhado por uma espécie de “equilíbrio instável”, ou metaestabilidade, em sua formação contínua. Nesse sentido, a complexa e recente era digital, paradoxalmente acompanhada de todos seus avanços e rugosidades (PIMENTA, 2016; SANTOS, 2008) viabilizaram extensos “conjuntos técnicos”, resultantes da evolução dos "objetos técnicos” que compõem os integram, e que hoje fazem parte da vida social de forma indelével pelos canais infor-comunicacionais (re)produzidos na sociedade contemporânea global e hipermoderna. A internet, por exemplo, é um "conjunto técnico" circunscrito a um "sistema técnico": o ciberespaço. Suas potências, tanto do conjunto como do sistema em si, são imensuráveis. 
Talvez tangenciem o limite da individuação humana apesar de serem elas mesmas os agentes de transformação e de turning do conhecimento humano.

Ao passo que considerarmos o papel do "objeto técnico" na dinâmica da cultura informacional contemporânea teremos, se torna necessário dar destaque ao aspecto da mediação tecnológica enquanto fenômeno infor-comunicacional. Nele encontramos formas de interação homem/computador, produção, reprodução e simulação de espaços sociais diversos que ora tangenciam-se, ora se transversalizam, ora sobrepõem-se, ora convergem à construção e reconstrução de dimensões espaço-temporais onde operam trocas de capitais, códigos, classificações, símbolos, memórias e informações.

Com efeito, essas mesmas tecnologias propiciaram a consolidação de um espaço novo de sociabilidade e, portanto, de conhecimento.

Ainda sobre esse espaço novo, no tocante ao seu contexto sociocultural e de seu habitus (BOURDIEU, 1990, p. 56) distinto, cabe ainda afirmar de que as mudanças nas formas como nos relacionamos com as informações e o conhecimento que produzimos, via dispositivos digitais marcados pela técnica e prática da convergência, poderiam interferir neste enraizamento do habitus e, por sua vez, em todo o cenário da cultura digital contemporânea.

Para a Ciência da Informação, debruçando-se nos apontamentos de Borko (1968), cabe complementar sua ideia ao afirmar que a era digital trouxe consigo novas propriedades e comportamentos advindos não somente de novas forças como de fluxos e usos mais complexos e plurais da informação. No ambiente digital, espaço relativamente recente, pois goza de pouco mais de 25 anos desde sua franca expansão ainda no início dos anos noventa, sua densidade de dados e informação surpreende a cada ano; assim como seus respectivos aparatos, objetos, técnicos desenvolvidos à reboque de seu acelerado desenvolvimento. Este recrudescimento dos meios de produção e circulação da informação acompanharam a demanda por acesso e a aplicabilidade do conhecimento tecnológico e científico às práticas da sociedade da informação e do conhecimento, além de incrementar uma reflexão quanto a suas implicações éticas (CAPURRO, 2001; 2005) e políticas.

No campo das ciências humanas, as faculdades e departamentos de história, ciências sociais, letras e filosofia até então estiveram grosso modo em uma espécie de "retaguarda" da inovação tecnológica quando o assunto era produção científica e 
suas respectivas metodologias empregadas no dia-a-dia da pesquisa. Nesse sentido, ao considerar o recente ambiente informacional, marcado pela experiência digital e seus objetos técnicos responsáveis por uma mediação infor-comunicacional sem precedentes, ao qual nos referimos anteriormente, seria correto considerar as $\mathrm{Hu}$ manidades Digitais enquanto uma verdadeira

$$
\begin{aligned}
& \text { zona de negociação, [onde se ressalta] a importância do espaço, co- } \\
& \text { nectando-se às disciplinas e incorporando-se em múltiplos modos de } \\
& \text { engajamento, tornando a tecnologia parte das humanidades digitais e } \\
& \text { o seu campo como uma arena para a inovação e reflexão (SVENSSON, } \\
& \text { 2012, online) }{ }^{2}
\end{aligned}
$$

Se pudéssemos pensar em uma espécie de "geopolítica" da comunicação científica, seria nela mesma que a conectividade acabou por apresentar um conjunto de desafios e incentivos à refle2 Entre colchetes, grifo nosso. xão e atuação em instituições e seus respectivos espaços tradicionalmente conhecidos como auxiliares à pesquisa histórica e sociológica, entre outras. Bibliotecas, arquivos, centros de documentação e referência, além de laboratórios e grupos de pesquisa na área de humanas precisaram inovar frente ao cenário que se delineava no qual o crescente volume e variedade de dados e informação provenientes de mídias, bases e plataformas diversos produziu não somente uma demanda como uma necessidade de lidar com tamanho horizonte de possibilidades.

No que concerne ao uso das tecnologias e seus respectivos reflexos no campo de interesse da Ciência da Informação à luz do que é discutido na Humanidades Digitais, é importante ter em perspectiva que as diferentes mídias de linguagem digital hoje disponíveis produzem pela convergência digital a possibilidade de sobreposição e "combinação de informações de tipos diferentes que, tradicionalmente, eram consideradas distintas uma vez que possuíam diferentes de produção e distribuição" (ROCKWELL, 2013, p. 22).

Dito isso, é fato que a cultura informacional atual, presente na hipermodernidade (LIPOVETSKY, 2004), juntamente com seus dispositivos (DELEUZE, 1991; 1999) (FOUCAULT, 1984; 1999; 2000) informacionais, são responsáveis pela forma como concebemos nossa relação com os aspectos da visibilidade, da memória, da informação e do conhecimento; ambos potencializados pela possibilidade da 
mediação, via recursos tecnológicos e suas possibilidades de acesso, convergência e circulação da informação; e pela desintermediação (ALMEIDA, 2014, p. 192193), onde o acesso e a produção de conteúdo informacional, incrementado pelo desenvolvimento de uma competência critica em informação, por uma estética informacional, pelo design ético e pelo objetivo de tornar a informação pública.

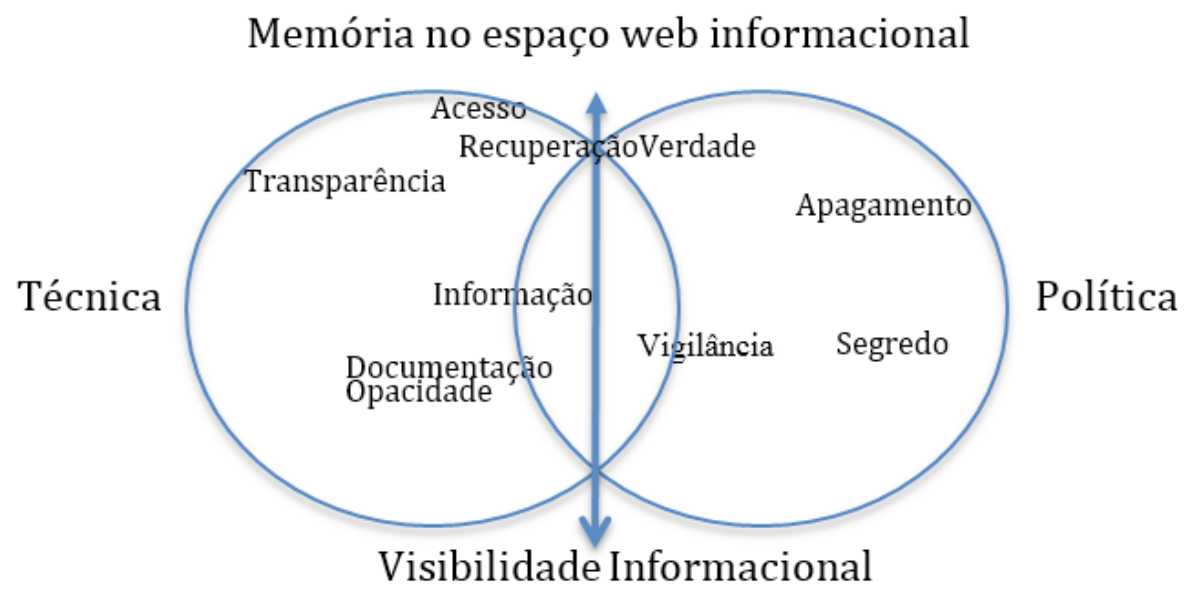

Figura 1 - Esquema cartográfico de disposição e interseção de elementos discursivos conceituais presentes tanto no nomus como na doxa dos respectivos campos do saber técnico e a político da informação. Fonte: Do próprio autor

O que sugerimos aqui, apesar de não nos considerarmos capazes no momento de desenvolver sinteticamente neste artigo sob o risco de desvirtuá-lo do proposto inicial, é que a reflexão sobre as humanidades digitais precisa cada vez mais adentrar o terreno filosófico, cultural e epistemológico de forma a participar, por exemplo, do debate em torno da questão da visibilidade informacional enquanto aspecto possível em face da articulação técnica x política presente em um estado cultural global, marcado por Lipovetsky e Serroy (2015, p. 371) como hipermodernidade, onde o apelo ao digital, mesmo na academia, acaba por ser ele próprio expressão e impressão dessa "sociedade-moda" na qual todos estamos imersos. Onde o "capitalismo-artista" chegou à ciência e à academia. "Pesquisador-artista" para uma "ciência-artista" onde a singularidade do que produzimos é mensurada pela contínua atualização, aceleração e crescimento dos meios a se produzir conhecimento com o objetivo de escapar da obsolescência da própria práxis científica. Infográficos, visualizações de dados, convergência digital, comunicação e tráfego multimodal de informações, interfaces e a ética do design informacional em prol do acesso público. 
Todos estes aspectos, visivelmente presentes no campo de produção das Humanidades Digitais, são de ordem da estética hipermoderna da cultura informacional. Portanto, compreender os fenômenos ali implicados pela cultura material que a ratifica, legitima e reproduz parece ser adequado.

Além do mais, compreender o fenômeno por meio de sua materialidade produtora não é novidade. McLuhan (2011), ao postular que "o meio era a mensagem", apontou em sua colocação que as extensões comunicacionais (e informacionais) criadas pela tecnologia humana eram, por si mesmas, o elemento fundamental inferidor de mudanças nas dimensões sociopolíticas e culturais do homem e, pois, objeto próprio de análise para além dos usos e informações que a sociedade produz a partir deles. Cabe considerar qual a posição das humanidades digitais nesse cenário. O que propomos é que ela é fruto do advento, da reprodução, massificação e circulação dessas mesmas "extensões" as quais mudaram a forma como nos relacionamos com o objeto, o problema e as metodologias para a construção do conhecimento nas humanidades.

\section{Considerações finais}

Ao considerarmos o postulado Latourniano: "mude os instrumentos, e você mudará toda teoria social que os acompanha" (LATOUR, 2009, p. 9). Parece-nos coerente acrescentar mais uma afirmação, capaz de explicitar as humanidades digitais. Para além de se pensar em uma nova teoria com base nos novos instrumentos, cresce a emergência de um pensar reflexivo sobre os novos instrumentos no campo até então não familiarizado com eles. Por isso a ideia de que as HD precisam se construir-se enquanto um campo auto-reflexivo parece bem acertada já que em muitos casos é a aplicação das tecnologias digitais voltadas às Humanidades que se tornam o seu objeto de estudo.

Ou seja, a transdisciplinaridade possível no campo das humanidades digitais acaba por viabilizar a construção de um objeto híbrido de estudo cujas atividades de investigação buscam lato sensu realizar uma espécie de "praxiologia" das mediações (ALMEIDA, 2014), ou dos processos desenvolvedores, de: (1) informação; (2) divulgação e comunicação científica; (3) de acesso público; (4) visibilidade; (5) mineração de dados; (6) competências ou literacias ou (7) de interfaces à produção 
do conhecimento.

Para Mayer-Schonenberger (2009), os recursos digitais apropriados, partilhados e reproduzidos parecem compor atualmente uma cultura de "bricolagem" nitidamente informacional, na qual estamos cada vez mais profundamente implicados e consolidando sua estrutura simbólica e econômica.

Essa cultura de bricolagem informacional afeta as formas pelas quais se dá o acesso à informação e sua apreensão, em vista dos múltiplos processos comunicacionais vigentes.

Neste ínterim, podemos afirmar que o crescente interesse pelas Humanidades Digitais é fruto destas novas formas de acesso, apreensão e circulação da informação e do conhecimento em ambientes digitais já que tal "bricolagem informacional" acabou por produzir uma nova criação; um novo objeto a ser estudado. À Ciência da Informação, cabe sinalizar a importância de debruçar-se sobre a paisagem que as $\mathrm{HD}$ vem criando pois à ela, a CI, será questionado cedo ou tarde maiores estudos e reflexões sobre um campo cuja informação, sua organização, juntamente com a tecnologia e sua orientação "pública" não nos deixam de dar sinais de crescimento nos últimos anos. Exemplo disso são os softwares, aplicativos, plataformas, recursos eletrônicos e digitais utilizados para a pesquisa e para a conjugação de dados e informações de bases diversas, visando sua divulgação na sociedade da informação. São estes “objetos técnicos” (SIMONDON, 1989) capazes não somente de mediar a informação, mas de produzir novas informações a partir de sua dinâmica singular.

\section{Referências}

ALMEIDA, M. A. N. Mediação e mediadores nos fluxos tecnoculturais contemporâneos. Informação \& Informação, v. 19, n. 2, 2014. Disponível em: <http://www.brapci.ufpr.br/brapci/v/a/15831>. Acesso em: 05 Dez. 2016.

BORKO, H. Information science: what is it? American Documentation, v. 19, n. 1, p. 3-5, jan. 1968.

BOURDIEU, P. The logic of practice. Stanford: Stanford University Press, 1990.

CAPURRO, R. Ética para provedores e usuários da informação. In: KALB, A.; ESTERBAUER, R.; RUCKENBAUER, H. W. (Orgs.). Cibernética: responsabilidade em mundo interligado pela rede digital. São Paulo: Loyola, 2001. O crescimento mundial da rede digital leva a uma ética global da informação? Revista Internacional de Teologia: Ciberespaço, Ciberética, Ciberteologia, v. 1, n. 309, p. 38-49, 2005. 
DELEUZE, G. A dobra: Leibniz e o barroco. Campinas: Papirus, 1991.

Que és un dispositivo? In: BALIBAR, E. et al. Michel Foucault, filósofo. Barcelona: Gedisa, 1999.

p. $155-163$.

FOUCAULT, M. Microfísica do poder. Rio de Janeiro: Graal, 2000.

História da sexualidade II: o uso dos prazeres. Rio de Janeiro: Graal, 1984.

Tecnologias del yo y otros textos afines. Barcelona: Paidós, 1990.

GOLD, M. K. Debates in the Digital Humanities. Minneapolis: University of Minnesota Press, 2012.

Disponível em: <https://muse.jhu.edu/>. Acesso em: 5 dez. 2016.

GONZALEZ DE GOMEZ, M. N. Novos cenários políticos para a informação. Ciência da Informação, Brasília, v. 31, n. 1, p. 2740, 2002. Disponível em: <http://www.scielo.br/pdf/ci/v31n1/a04v31n1.pdf>. Acesso em: 02 dez. 2016.

JORENTE, M. J. V.; SILVA, A. R.; PIMENTA, R. M. Cultura, memória e curadoria digital na plataforma sniic. Liinc em revista, v. 11, n. 1, 2015. Disponível em: <http://liinc.revista.ibict.br/index.php/liinc/article/ view/800/533>. Acesso em: 05 dez. 2016.

LATOUR, B. 'Tarde's idea of quantification'. In: CANDEA, M. The social after gabriel tarde: debates and assessments. London: Routledge, 2009. Disponível em <http://www.bruno-latour.fr/sites/default/files/ 116-CANDEA-TARDE-FR.pdf>. Acesso 23 mar. 2014.

LIPOVETSKY, G. Os tempos hipermodernos. São Paulo: Barcarolla, 2004.

LIPOVETSKY, G.; SERROY, J. A estetização do mundo: viver na era do capitalismo artista. São Paulo: Companhia das Letras, 2015.

MARTELETO, R. M. Cultura informacional: construindo o objeto informação pelo emprego dos conceitos de imaginário, instituição e campo social. Ciência da Informação, v. 24, n. 1, p. 1-8, 1995. Disponível em: <http://www.brapci.ufpr.br/brapci/v/a/810>. Acesso em: 07 Dez. 2016

MAYER-SCHÖNBERGER, V. Delete: the virtue of forgetting in the digital age. Princeton: Princeton University Press, 2009.

MCLUHAN, M. Understanding media: the extensions of man. Edited by W. Terrence Gordon. Berkeley, CA: Gingko Press, 2011.

NEGROPONTE, N. A vida digital. São Paulo: Companhia das Letras, 1995.

PIMENTA, R. M. As rugosidades do ciberespaço: um contributo teórico aos estudos dos web espaços informacionais. Informação \& Sociedade: Estudos, v. 26, n. 2, 2016. Disponível em: <http://www.ies.ufpb. br/ojs/index.php/ies/article/view/28116>. Acesso em: 07 dez. 2016.

Big Data e controle da informação na Era digital: tecnogênese de uma memória a serviço do mercado e do estado. Tendências da Pesquisa Brasileira em Ciência da Informação, v. 6, p. 7-24, 2013. 
ROCKWELL, G. Is humanities computing an academic discipline? In. TERRAS, Melissa; NYHAN, Julianne. VANHOUTTE, Edward. (Eds.) Defining Digital Humanities: a reader. England: Ashgate, 2013.

SANTOS, M. A natureza do espaço: técnica e tempo, razão e emoção. São Paulo: USP, 2008.

SCHRIEBMAN, S.; SIEMENS, R.; UNSWORTH, J. (Eds.). A companion to digital humanities. Oxford: Blackwell, 2004. Disponível em: <http://www.digitalhumanities.org/companion/>. Acesso em 02 dez. 2016.

SIMONDON, G. Du mode d'existence des objets techniques. 3. ed. Paris: Aubier, 1989.

L'Individuation à la lumière des notions de forme et d'information. Grenoble: Millon, 2005. SVENSSON, P. Envisioning the digital humanities. Digital Humanities Quarterly. v. 6, n. 1, 2012. Disponível em: <http://www.digitalhumanities.org/dhq/vol/6/1/000112/000112.html>. Acesso em: 04 dez. 2016. THATCAMP. Manifesto das humanidades digitais. Paris: ThatCamp [The Humanities and Technology Camp]. 2011. Disponível em: <http://tcp.hypotheses.org/category/manifeste>. Acesso em: 29 nov. 2016. VAZ, P. Esperança e excesso. In: PARENTE, A. (Org.). Tramas da rede: novas dimensões filosóficas, estéticas e políticas de comunicação. Porto Alegre: Sulina, 2004. p. 189-208. 